\title{
Design And Implementation Of Solar Charge Controller With P\&O Mppt For Light-Fishing In Ujung Pangkah, Gresik
}

\author{
$1^{\text {st }}$ Wahyu Ardi Santosa \\ Electrical Engineering \\ Sepuluh Nopember Institute of \\ Technology \\ Surabaya, Indonesia \\ wahyu15@mhs.ee.its.ac.id
}

\author{
$2^{\text {nd }}$ Sjamsjul Anam \\ Electrical Engineering \\ Sepuluh Nopember Institute of \\ Technology \\ Surabaya, Indonesia \\ anam@ee.its.ac.id
}

\author{
$3^{\text {rd }}$ Feby Agung Pamuji \\ Electrical Engineering \\ Sepuluh Nopember Institute of \\ Technology \\ Surabaya, Indonesia \\ febyagungpamuji@gmail.com
}

\begin{abstract}
Bagan tancap is a conventional fishing using diesel as its main source. This conventional method needs to be replaced with an eco-friendly and easy to use system, namely solar panels. The solar panels power is just limited by time so the stability of the system is poorly maintained that needs to be a battery as a storage of energy to improve system stability. However, the power that is not optimal causes the charging battery to take longer and not be constant with periods of weather and irradiation coditions. The charging battery without MPPT it tends not to be optimal because the solar panel does not operate at its maximum value. MPPT with perturb and observe algorithms can maximize power on solar cells with tracking speeds that depend on the response speed of the converter. While boost coverter has the ability to maintain potential differences that are tailored to the battery specifications and keep the current and voltage ripple values relatively small. For this reason, this final project will design and implement solar charge controller equipped with MPPT $P$ $\& O$ (Perturb and Observe) and boost converter, this method can maximize the power of the solar panel by $97.84 \%$ with a faster charging time for 27 minutes.
\end{abstract}

Keywords-Light Fishing, MPPT, Perturb and Observe, Solar Charge Controller

\section{INTRODUCTION}

The use of lights as a fishing aid developed rapidly after the discovery of electric lights. Innovation of Light Emitting Diode (LED) lamps as energy saving lamps has a great opportunity to be used in fishing activities. LED lights require low voltage and current so that they can be combined with renewable energy sources to encourage the realization of capture fisheries that are more environmentally friendly.

One of the abundant and easily renewable energy sources is the sun. Solar energy has the advantage of minimum maintenance and pollution-free, but currently the price of solar panels as a tool to convert solar energy into electrical energy is still relatively expensive and energy conversion efficiency is still low.

So there is a need for storage or batteries to store electrical energy that comes from renewable energy from the sun, so that the stability of the system is more maintained, especially when the irregular solar irradiance. Electrical energy from solar panels to batteries can be maximized and controlled using a solar charge controller. The solar charge controller is a technology that can be relied upon to reduce dependence on electric energy sources generated from diesel. In solar energy conversion systems, the solar charge controller becomes the main function in the system which is designed to protect the battery during the recharging process. Solar Charge Controller uses several components such as power supply, solar panel voltage and current sensors, solar current protection or reverse voltage, relays, current and voltage sensors for batteries, and LED indicators for effective operation [1]. The main function of the charge controller in stand-alone solar panel systems is to keep the battery at the highest state of charge (SOC) and protect overcharging from solar panel supplies. Ideally, the charge controller directly controls the SOC of battery.

Without using a charge controller, the current from the solar panel will flow to the battery depending on the irradiance, whether the battery needs charging or not. If the battery is fully charged, unchecked charging will cause overcharging, which can cause gassing effects, electrolyte losses, internal heat, and acceleration of grid corrosion. The gassing effect can occur because the active material in the battery has an excess charge, so that gas will form and reduce the charging efficiency of the battery. In fact the charge controller maintains a "healthy" battery condition and extends battery life. These undesirable conditions can be prevented by the use of a solar charge controller. Most types of lithium-ion batteries cannot accept overcharge conditions without damaging or security problems, and BMS (Battery Management System) is usually used which maintains these batteries independently of this charge controller. In this study using the three stage charging method to maintain battery security, fast charging, and full charging without overcharging.

\section{RESEARCH METODOLOGY}

\section{A. Battery}

Batteries in solar panel systems are often needed for charging and discharging. High acid Lead Acid batteries are typically used for applications in solar panels. Gel-type Lead Acid batteries are used for remote applications where maintenance treatment is required.

For battery applications that are easy to carry everywhere Nickel-Cadmium or Ni-Metal batteries are usually used. Battery life varies from 3 to 5 years. Battery life depends on the charging/discharging cycle, temperature and other parameters.

Batteries for solar panel applications are designed to meet the following characteristics [2]:

1. Low price

2. High energy efficiency 
3. Long battery life

4. Easy maintenance

Lead-acid batteries are made using lead-based electrodes and lattices. Calcium might be added as an addictive material to provide mechanical strength. The formulation of active ingredients is some lead oxide. For optimal performance, the battery manufacturer has their own formula. Electrolytes are liquid solutions of sulfuric acid $\left(\mathrm{H}_{2} \mathrm{SO}_{4}\right)$. Active ingredients including electrochemicals are electrolytes, positive and negative electrodes. The negative electrode in the battery contains sponge-lead $(\mathrm{Pb})$ and the positive electrode is leadoxide $\left(\mathrm{PbO}_{2}\right)$.

There are several types of lead-acid batteries that will be discussed as follows [3]:

1. Flood: flooded type is a taxi type battery and a battery for starting a traditional engine consisting of a solution made of electrolytes. When it runs out, users can easily add distilled water.

2. Sealed: Different from the flooded type, the sealed battery is not permitted by the user to enter the battery cell through the internal structure, just as the battery is flooded and only a number of arrangements with a slight modification. The plant must be sufficiently convincing of the amount of acid in the battery cell chamber so that the battery allows it to withstand chemical reactions under normal use.

3. VRLA (Valve Regulated Lead Acid): VRLA batteries give priority to valve control, releasing hydrogen gas and oxygen during charging.

4. AGM (Absorbed Glass Matte): Electrolytes are very tightly closed with a disc of the active ingredient in an AGM type battery, in theory it can increase charge and discharge efficiency. This battery, actually a type of sealed VRLA battery, has become very popular in starting engines.

5. GEL: Gel cell batteries are considered drier than AGM batteries but have the same model because, both of them consist of closed electrolytes. The electrolytes in GEL cells have silica additives which cause hardening. The recharging voltage in this type of cell is lower than other forms of leadacid batteries. This allows the cell to be very sensitive to overcharging.

\section{B. MPPT (Maximum Power Point Tracking)}

The efficiency of the solar panel system varies according to the irradiance level. The efficiency of solar panel cells is low when the radiation level is low. The average efficiency is $12 \%$, which the use of monocrystalline silicon cells can reach efficiencies of up to $15 \%$ [4]. So the solar panel system needs to be regulated for operation at the maximum power point or MPP (Maximum Power Point) during the iradian. In this study, MPPT is used to keep the MPP point constant for varying degrees of radiation.

Several MPPT algorithms have been developed and implemented such as hill climbing (HC), perturb and observe $(\mathrm{P} \& \mathrm{O})$, incremental conductance (IncCond), and fuzzy logic control (FLC) [5].

The difference between each method above is efficiency, ease of application, number of sensors, response speed and tracking system. The perturb and observe ( $\mathrm{p} \& \mathrm{o})$ algorithm is the most popular method for tracking maximum power on

solar panels. The flowchart of the P\&O algorithm can be seen in Figure 3.

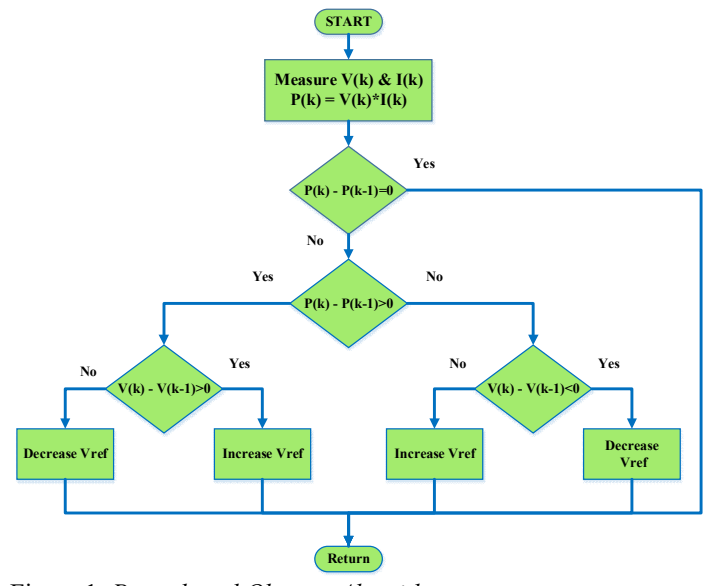

Figure 1. Perturb and Observe Algorithm

The working principle of the $\mathrm{P} \& \mathrm{O}$ algorithm depends on the process of interrupting (perturb) the solar panel working voltage periodically. The solar panel is connected directly to the DC-DC converter, which then interrupts the working voltage of the solar panel by changing the DC-DC converter duty cycle.

\section{Solar Charge Controller}

This allows the cell to be very sensitive to In this study using the three stage charging method to maintain battery security, fast charging, and full charging without overcharging. The charge controller method can be seen as shown in Figure 2 and the description is as follows:

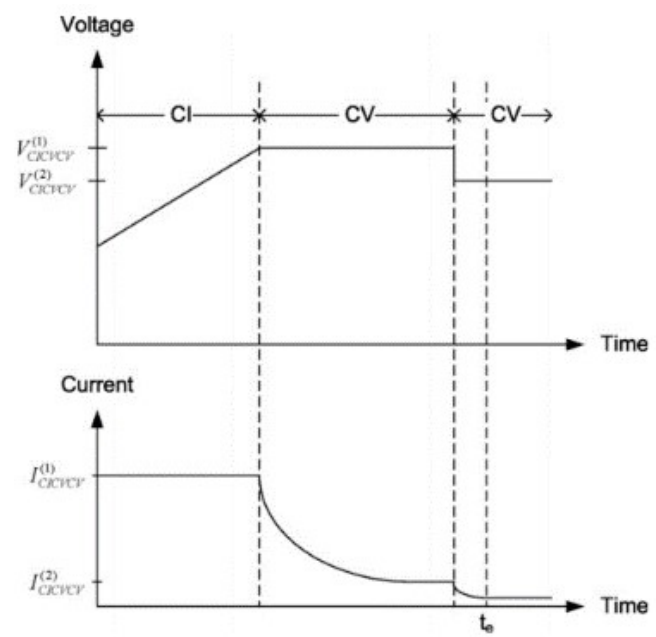

Figure 2. Three-Stage Battery Charging Method

1. Bulk Charging Stage (Constant Current Charging)

At the Bulk charging stage it includes recharging batteries from $20 \%$ SOC to $80 \%$ SOC, where the current used for charging is kept constant and the battery voltage will increase. At this stage the battery is charged with high current value which is basically the rating current for charging the battery. Chargers in this study will provide rating currents to charging capacity ( $10 \%$ of battery capacity in Ah). So that the MPPT is activated at this charging stage. 2. Absorption Charge Stage (Constant Voltage Charging) 
At this stage the charging method is based on the battery voltage constant to reach its upper limit safe value, Vabs. The battery current will gradually decrease when internal resistance increases during the charging process. The absorption phase ends when the state of charge (SOC) reaches 90 - 95\%. This can be detected when the current decreases to approximately $20 \%$ of the maximum charging current.

3. Float Charge Stage (Constant Voltage Charging)

After the battery has reached a fully charged condition, the voltage is reduced to a low level, Vf to extend battery life and reduce the effect of gassing. The floating voltage keeps the battery in standby condition for use.

\section{IMPLEMENTATION RESULT}

\section{A. Work System}

The system as a whole includes solar panels, boost converters, charge controllers and batteries as shown in Figure 3.

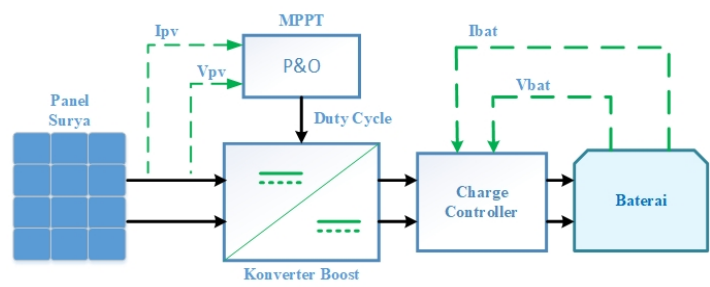

Figure 3. Block Diagram of Solar Charge Controller with MPPT

actuator from the MPPT system using the perturb and observe algorithm.

In the modeling it is only shown a block diagram of a solar charge controller system in the form of a subsystem in which there are several circuits. The purpose of modeling is useful to make it easier for readers to see the system as a whole.

\section{B. Implementation}

All components used in the implementation of the Solar Charge Controller system follow the availability of components on the market. The component value in the implementation is a greater value than the component value that has been designed. It aims to anticipate the converter in the DCM state.

Implementation of the solar charge controller system can be seen in Figure 4 which consists of several components, namely $80 \mathrm{Wp}$ solar panel modules, SCC (Solar Charge Controller), MPPT consisting of boost converters and Arduino microcontrollers which are given a $\mathrm{P} \& \mathrm{O}$ (Perturb and Observe) algorithm, DC 12V Supply which is used to supply MOSFET drivers, LCD displays to display solar panel voltage values, battery voltages, and battery currents, and LED indicators to indicate battery conditions when empty or full.

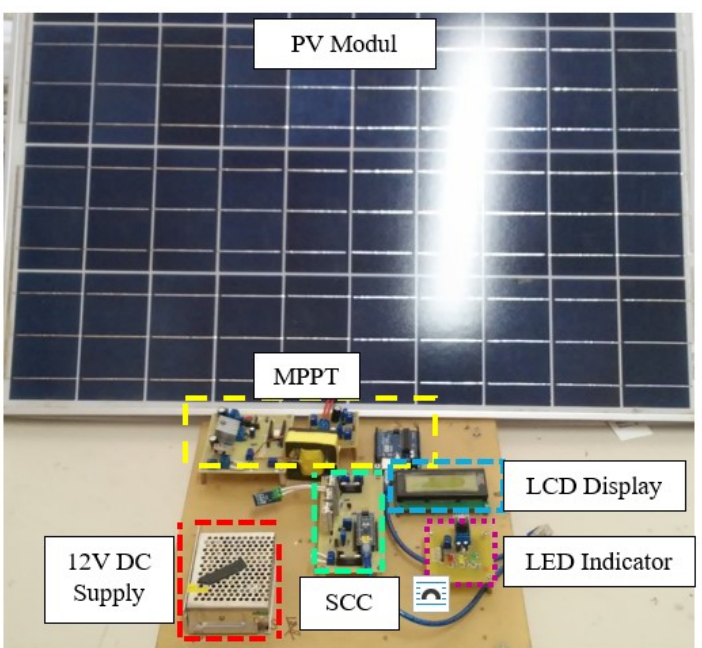

'Figure 4. Implementation of Solar Charge Controller with MPPT $\perp$ in the solar charge controller system implementation as shown in Table 1.

Table 1.

Component of Solar Charge Controller

\begin{tabular}{|c|c|}
\hline Solar Panel Component & Value \\
\hline Solar Panel & Rayden Solar RD80P-18 \\
\hline Power V $\mathrm{MPP}_{\mathrm{MPP}}$ & $80 \mathrm{WP}$ \\
\hline Voltage $\mathrm{V}_{\mathrm{MPP}}$ & $17,5 \mathrm{~V}$ \\
\hline Current I $\mathrm{MPP}$ & $4,57 \mathrm{~A}$ \\
\hline Boost Converter & Nilai \\
\hline Microcontroller & Arduino Uno \\
\hline Switching frequency & $50 \mathrm{kHz}$ \\
\hline Inductor & $219 \mu \mathrm{H}$ \\
\hline Capasitor & $470 \mu \mathrm{F} / 53 \mathrm{~V}$ \\
\hline Diode & MUR 1560 \\
\hline MOSFET & IRFP4332 \\
\hline MOSFET driver & FOD3182 \\
\hline Supply Driver MOSFET & $12 \mathrm{Vdc}$ \\
\hline Sensor & Nilai \\
\hline Voltage sensor & Multiturn $100 \mathrm{k} \Omega$ \\
\hline Curremt sensor & ACS 712 \\
\hline
\end{tabular}

Ordinary Solar Charge Controller (SCC) systems will be compared to SCCs equipped with MPPT using the Perturb and Observe $(\mathrm{P} \& \mathrm{O})$ algorithm to find out which techniques are more effective and efficient. Tests on the two charging techniques are carried out at the same time and the solar radiation levels are relatively the same.

$80 \mathrm{Wp}$ solar panel and 18Ah lead-acid battery with similar specifications are used. On the first day, battery charging was tested using the usual SCC method. Then the second day was tested using the SCC method with MPPT $\mathrm{P} \& O$. These two techniques will be compared to find out the comparison of the results of the large charging capacity of the battery on the battery with the same specifics. The test was carried out in the AJ101 Building, Department of Electrical Engineering ITS starting at 09.00 WIB until finished. Data collection was carried out for approximately 4.5 hours.

In the initial state of testing, the battery voltage has a voltage of $12.42 \mathrm{~V}$. Figure 6 shows the results of battery 
testing using the SCC-MPPT method. There was a bulk charging phase (constant current charging) in which the current value at that phase was relatively constant at $3.47 \mathrm{~A}$. The bulk phase lasts for 3 hours 6 minutes until the battery voltage is $14.17 \mathrm{~V}$. Then the charging mode changes to absorption charging (constant voltage charging) where the battery voltage will slowly rise to $14.42 \mathrm{~V}$. In the absorption phase simultaneously the battery current drops slowly to near zero. When the battery current reads C / 100, the current test reads $0.195 \mathrm{~A}$, then the charging mode becomes float charging. At this stage the voltage is kept in the range of 13.5 $-13.9 \mathrm{~V}$ or called standby used. In this charging technique the battery voltage cutoff is done when the battery voltage is $13.76 \mathrm{~V}$.

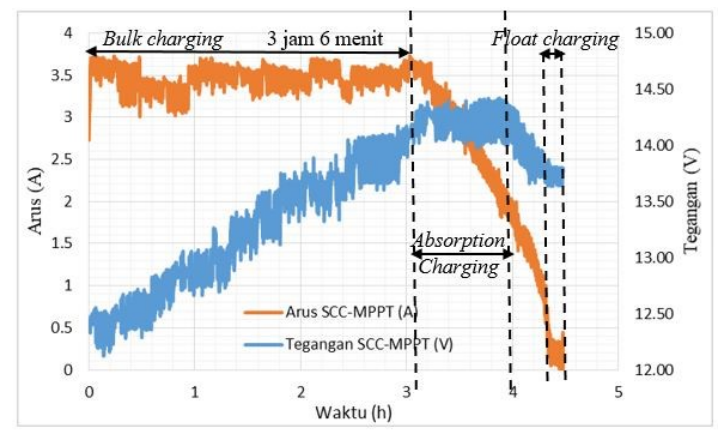

Figure 5. The Result of Solar Charge Controller with $P \& O$ $M P P T$

Then the battery charging test with SCC without MPPT is also carried out where the charging technique applied is still the same as in the SCC-MPPT test. Figure 6 shows the results of SCC testing without MPPT.

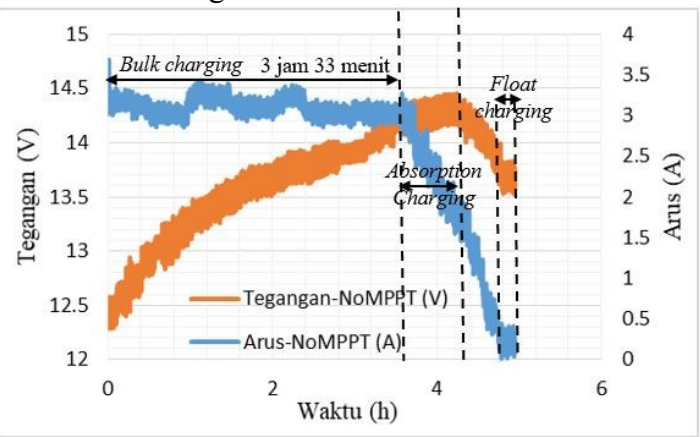

Figure 6. The Result of Solar Charge Controller without $P \& O$ $M P P T$

In this test method the bulk charging phase lasts longer which is 3 hours 33 minutes until the voltage is $14.26 \mathrm{~V}$ with a relatively constant battery current of 3.09A. The battery voltage is used as a reference for the transition from changing the bulk mode to absorption mode where the battery voltage slowly rises to a voltage of $14.39 \mathrm{~V}$. With the end of the bulk phase, the battery current slowly drops to C /
100 , which is $0.199 \mathrm{~A}$. When the battery current reaches $\mathrm{C} /$ 100 , the charging mode becomes float charging mode. The float charging mode keeps the battery voltage in standby mode. The final battery voltage for this charging method is $13.74 \mathrm{~V}$.

After the data collection of the two charging methods has ended, the battery is removed from the SCC system and then allowed to stand for 20 minutes. Obtained that the voltage on the battery using the SCC-MPPT method has a final voltage of 13.43 greater than $0.11 \mathrm{~V}$ than battery voltage that uses the SCC method without MPPT which has a final voltage value of $13.32 \mathrm{~V}$. The difference in the final voltage can be used as a reference to determine the battery capacity, that by using the SCC-MPPT charging method has a battery capacity greater than the capacity of the battery that uses the SCC charging method without MPPT after charging is stopped. Overall input energy found that batteries with the SCCMPPT charging method get $24.33 \%$ more energy than batteries with the SCC technique without MPPT.

\section{CONCLUSION}

Based on the results of the simulation and implementation, the Solar Charge Controller system equipped with MPPT Perturb and Observe can be concluded as follows:

1. The use of MPPT with Perturb and Observe algorithm control on the Solar Charge Controller can shorten the battery charging time by 27 minutes from the Solar Charge Controller method without MPPT.

2. MPPT with Perturb and Observe algorithm control on the Solar Charge Controller system in this study can maximize the elongation of solar panels by $97.84 \%$.

3 . The battery charging method with the Solar Charge Controller-MPPT gets $24.33 \%$ more energy than the battery charging method with the Solar Charge Controller without MPPT.

\section{REFERENCES}

[1] N. Khera, N. Rana, N. Si, S. K. Sahoo, M. Balamurugan, S. P. Karthikeyan, and J. Raglend, "Design of Charge Controller for Solar PV Systems," 2015 Int. Conf. Control. Instrumentation, Commun. Comput. Technol., pp. 149-153, 2015

[2] A. Jossen, J. Garche, and D. U. Sauer, "Operation conditions of batteries in PV applications," vol. 76, pp. 759-769, 2004

[3] M. Killi and S. Samanta, "Modified Perturb and Observe MPPT Algorithm for Drift Avoidance in Photovoltaic Systems," vol.

[4] P. G. Scholar, "Modeling and Performance Analysis of Perturb \& Observe , Incremental Conductance and Fuzzy Logic MPPT Controllers," vol. 2017, pp. 13-18, 2017

[5] G. Mehta, M. Dwivedi, G. Noida, V. K. Yadav, and G. Noida, "Comparison of Advance Intelligence Algorithms for Maximum Power Point Tracking,” pp. 262-267, 2017. 